\title{
Opioid substitution and antagonist therapy trials exclude the common addiction patient: a systematic review and analysis of eligibility criteria
}

Brittany B. Dennis ${ }^{1}$, Pavel S. Roshanov², Leen Naji ${ }^{3}$, Monica Bawor ${ }^{4}$, James Paul ${ }^{5}$, Carolyn Plater ${ }^{6}$, Guillaume Pare ${ }^{1}$, Andrew Worster ${ }^{6,7}$, Michael Varenbut ${ }^{6}$, Jeff Daiter ${ }^{6}$, David C. Marsh ${ }^{6,8}$, Dipika Desai ${ }^{9}$, Zainab Samaan ${ }^{1,9,10,11}$ and Lehana Thabane $e^{1,12,13^{*}}$

\begin{abstract}
Background: Eligibility criteria that result in the exclusion of a substantial number of patients from randomized trials jeopardize the generalizability of treatment effect to much of the clinical population. This is important when evaluating opioid substitution and antagonist therapies (OSATs), especially given the challenges associated with treating the opioid-dependent population. We aimed to identify OSAT trials' eligibility criteria, quantify the percentage of the clinical population excluded by these criteria, and determine how OSAT guidelines incorporate evidence from these trials.

Methods: We performed a systematic review to identify the eligibility criteria used across trials. We searched Medline, EMBASE, PsycINFO, Web of Science, Cochrane Library, Cochrane Clinical Trials Registry (CTR), World Health Organization International CTR Platform Search Portal, and the National Institutes of Health CTR databases from inception to January 1, 2014. To quantify the effect of trials' eligibility criteria on generalizability, we applied these criteria to data from an observational study of opioid-dependent patients $(n=394)$. We then accessed the Canadian, American, British, and World Health Organization (WHO) OSAT guidelines to evaluate how evidence is used in the recommendations.

Results: Among the 60 trials identified the majority ( $\geq 50 \%$ of trials) exclude patients with psychiatric $(60 \%)$ and physical comorbidity (51.7\%). Additionally, we found 19 trials exclude patients with current alcohol/substance-use problems (31.7\%), and 29 (48.3\%) exclude patients taking psychotropic medications. These criteria were restrictive and in some cases rendered $70 \%$ of the observational sample ineligible. North American OSAT guidelines made strong recommendations supported by evidence with poor generalizability. National Institute of Health and Care Excellence (NICE) and WHO guidelines for opioid misuse provide a critical assessment of the literature used to inform their recommendations.
\end{abstract}

Conclusions: Trials assessing OSATs often exclude patients with concurrent disorders. If the excluded patients respond differently to treatment, results from these trials are likely to overestimate the true effectiveness of OSATs. North American guidelines should consider these limitations when drafting clinical recommendations.

Keywords: Opioid addiction, Opioid dependence, Opioid use disorder, Generalizability, Comorbidity, Psychiatric comorbidity, Methodology, Methadone maintenance treatment

\footnotetext{
* Correspondence: thabanl@mcmaster.ca

'Department of Clinical Epidemiology and Biostatistics, McMaster University, 1280 Main Street West, Hamilton, ON L8S 4L8, Canada

${ }^{12}$ Centre for Evaluation of Medicine, 25 Main Street West, Hamilton, ON L8P

$1 \mathrm{H} 1$, Canada

Full list of author information is available at the end of the article
}

(c) 2015 Dennis et al. Open Access This article is distributed under the terms of the Creative Commons Attribution 4.0 International License (http://creativecommons.org/licenses/by/4.0/), which permits unrestricted use, distribution, and reproduction in any medium, provided you give appropriate credit to the original author(s) and the source, provide a link to the Creative Commons license, and indicate if changes were made. The Creative Commons Public Domain Dedication waiver (http://creativecommons.org/publicdomain/zero/1.0/) applies to the data made available in this article, unless otherwise stated. 


\section{Background}

Opioid addiction is a chronic disorder with several risk factors contributing to its development and treatment course [1-3]. The global impact of opioid use is apparent and according to the United Nations Office on Drugs and Crime there were an estimated 26.4 to 36 million (0.03\% global population) people engaging in illicit opioid use in 2012 [4]. Within the US alone 2.1 million people are estimated to be suffering from a prescription opioid addiction [5]. The cost of opioid addiction to both patients and society is high, with estimates in the range of 55.7 billion US dollars [6]. A recent investigation from the RAND provides assessments of the costs of opioid addiction and estimate a range from $€ 2,627$ to $€ 60,665$ per person, per year. These estimates are comprised of data from American, Australian and Canadian populations and quote the most generalizable estimates encompassing the highest scope of costs (health care, lost worker productivity) at $€ 21,904$ per person per year [7].

Despite its high prevalence and global impact, [8] there remain few medication-assisted treatments for opioid addiction. The treatments are known collectively as opioid substitution and antagonist therapies (OSATs) and include both opioid agonist and antagonist treatments. Methadone, buprenorphine, buprenorphine-naloxone and naltrexone, [9] are among the regularly used treatments for addiction patients, with methadone remaining the most commonly prescribed [9]. Patients with opioid dependence are among the hardest to manage and retain in treatment $[10,11]$. Their transient lifestyle, extensive social issues, and physical comorbidities contribute to the difficulties of treatment. Less than $15 \%$ of methadone patients successfully finish their treatment as intended, [10, 11] and those who leave treatment have high susceptibility for human immunodeficiency virus (HIV), relapse, and death $[10,11]$. When faced with the responsibility of treating such complex and vulnerable populations we are expected to trust the recommendations put forward in the clinical guidelines.

Guidelines rely heavily on the evidence from stringently designed trials and meta-analyses to inform their recommendations [12-15]. Strict eligibility criteria can limit the generalizability of clinical research and leave clinicians guessing as to the effectiveness of interventions in many of their patients [16]. For instance, trials on treatments for opioid dependence commonly exclude patients with psychiatric comorbidities [17-25] in an effort to reduce noncompliance and determine whether a treatment works under optimal conditions. Such selective exclusion of difficult-to-treat patients may inflate the benefits we expect from our treatments. Patients with opioid dependence are known for having comorbid physical and psychiatric disorders [26-31] and the presence of such disorders can adversely affect their outcomes [32-34]. For instance, depressed people receiving opioid substitution therapy (OST) are more likely to consume illicit substances compared to counterparts who do not suffer from depression [32]. Since the prevalence of depression among opioid-dependent patients is high, [31] their exclusion from OSAT trials may bias the results and create inflated estimates of treatment effect. The complexities associated with managing opioid-dependent patients demand the need for thorough clinical guidelines. Accordingly, there is an enormous responsibility to ensure guidelines: (1) rely on the up-to-date evidence with high internal validity; (2) provide information on the populations that may respond differently to treatment and; (3) are transparent about the limitations of the evidence and their ability to provide strong recommendations. Assessment of the generalizability of OSAT trials to real practice and identification of important factors limiting generalizability are key steps in translating the evidence generated by these trials into practice.

While the impact of strict inclusion criteria on the generalizability of trial evidence has been previously evaluated in addiction research, [35-40] these studies are focused on alcohol- and cannabis-dependent populations, where the inclusion criteria and clinical implications may vary greatly from that of opioid-dependent populations. To our knowledge no study has investigated the eligibility criteria of OSAT trials. We set out to: (1) identify OSAT trials' eligibility criteria and other design characteristics; (2) quantify the proportion of the clinical population excluded by these criteria and; (3) determine how the most recent American, Canadian, British, and World Health Organization (WHO) OSAT treatment guidelines incorporate evidence from these trials.

\section{Methods \\ Review}

The protocol for this systematic review has been previously registered (Prospero ID: CRD42013006507) and described elsewhere [41]. The protocol for this review details a larger network meta-analysis currently in progress [41]. Briefly, we performed a systematic review to identify all randomized controlled trials (RCTs) evaluating the effect of a substitute opioid therapy for improving treatment response in opioid-dependent patients. We searched Medline, Excerpta Medica DataBase (EMBASE), PsycINFO, Web of Science, Cochrane Library, Cochrane Clinical Trials Registry (CTR), WHO International CTR Platform Search Portal, and the National Institutes of Health (NIH) CTR databases from inception to January 1, 2014. We asked each primary investigator listed on the $\mathrm{NIH}$ Clinical Trial Registry from studies deemed eligible from the title screen of the NIH trial library to submit a list of publications resulting from their trial. We also hand 
searched all Cochrane reviews evaluating the effectiveness of any OSAT to identify additional studies.

We included only studies evaluating the effectiveness of any opioid agonist or antagonist substitution therapy in patients with opioid addiction. Studies evaluating the effect of OSAT on specialized populations including cocaine- or alcohol-dependent patients were excluded. We will highlight again that the trials used for this review were identified as part of a larger network meta-analysis aiming to evaluate the impact of different OSTs in the general opioid addiction patient populations. Studies included were required to investigate the efficacy of an OSAT using one or more of the outcomes of interest: illicit substance use, treatment attrition, criminal behavior, mortality, physical and psychological well-being as well as adverse events. We placed no age or language restrictions on our search. However, we did require all studies be primary investigations with direct comparison groups (separated by a treatment or placebo). No studies evaluating a single treatment were included (e.g., cohort, cross-sectional studies). We extracted information on the stated trial objectives, eligibility criteria, and study design. All trials eligible for inclusion were subject to risk of bias assessment using the Cochrane Risk of Bias Tool [42]. We used the kappa statistic to assess inter-rater agreement, [43], which is preferable to percent agreement calculations since it takes into account any agreement occurring by chance. Kappa values range from 0 to 1 , with values closer to 1 indicating a higher level of agreement [43]. Disagreements during the screening and abstraction process were resolved by consensus. This review adheres to the reporting standards set out by the Preferred Reporting Items for Systematic reviews and Meta-Analyses (PRISMA) guidelines [44].

We then applied trials' reported eligibility criteria to a sample of 394 opioid-dependent patients participating in the GENetics of Opioid Addiction (GENOA) study, a collaboration between McMaster University and the Canadian Addiction Treatment Centres (CATC).

\section{GENetics of Opioid Addiction (GENOA) prospective cohort study design}

GENOA is an ongoing observational study of the genetic, biological, and social determinants of treatment response for opioid-dependent patients. The GENOA population is made up of opioid addiction patients actively receiving methadone treatment at a CATC facility. The CATC (formerly known as the Ontario Addiction Treatment Centre) are the largest network of methadone addiction treatment facilities in North America - with over 12,000 patients and 57 clinical sites across Canada. Over the past 20 years CATC has treated over 50,000 patients.

Although changes were made to enhance the study's feasibility and internal validity, the findings and details of methodology employed during the GENOA pilot phase are described elsewhere [45]. Changes made following the pilot phase include: relaxing eligibility criteria, utilizing a prospective cohort design with a follow-up duration of 12 months, and integrating the use of validated tools such as the Brief Pain Inventory (BPI) to assess pain [46], the Mini International Neuropsychiatric Interview version 6.0 (MINI) [47] to assess for psychiatric comorbidities, and the Maudsley Addiction Profile (MAP) instrument to assess addiction severity across personal, physical, and social functioning domains [48]. To be eligible for GENOA participants were required to be at least 18 years old and able to provide informed consent.

GENOA participants are opioid addiction patients receiving methadone for the treatment of opioid dependence. GENOA participants are recruited directly from CATC methadone treatment facilities. Participants provide an initial blood sample as well as addiction severity, pain, and psychiatric assessment at the baseline interview. Participants also provide urine samples to assess for substance use. Over the course of their 12-month follow-up GENOA participants are asked to partake in additional addiction severity assessments using the MAP [48] as well as urine toxicology screening at 3-month intervals.

The CATC is made of up 57 clinical facilitates administering pharmacological therapies for opioid addiction including methadone and buprenorphine. The CATC program offers clinical services including clinical interview to assess opioid dependence according to Diagnostic and Statistical Manual of Mental Disorders, Fourth Edition (DSM IV) criteria, medical examination and laboratory tests, where appropriate, supervised urine testing and initiation of treatment plan. CATC comprises the largest network of addiction treatment facilitates in North America treating over one-third of Ontario's opioid addiction population. From rural northern Ontario to populous downtown Toronto there is substantial variability in the geographic and economic populations CATC serves, offering a healthy case mix of patients being recruited into the GENOA study. The social, economic, and geographical discordance between CATC sites (both in general and those included in GENOA) increases our confidence in the generalizability of this sample.

We searched www.guidelines.gov for the most recent American and Canadian guidelines with the terms "opioid dependence," "opioid addiction," and "opioid substitution treatment." These search terms were used individually for three separate searches. We also used the National Institute for Health and Care Excellence (NICE) to identify the most recently published clinical guidelines for substitute opioid therapies used by the National Health Service in the UK. WHO guidelines were accessed directly from http://whqlibdoc.who.int/publications/2009/ 9789241547543_eng.pdf. We extracted information on recommendations made by each guideline, the grade 
assigned to that recommendation, evidence cited by the guideline, any cautions regarding clinical subgroup effects, and whether the guideline discussed the populations in which the interventions were tested.

The guidelines were also subject to additional evaluation using specific domains from the Appraisal of Guidelines for Research and Evaluation II (AGREE) Instrument. The AGREE II instrument is a validated and reliable tool used to assess the quality of clinical guidelines $[49,50]$. The instrument comprises 23 items organized into six quality domains: scope and purpose; stakeholder involvement; rigor of development; clarity of presentation; applicability; and editorial independence [49]. We chose to assess the guidelines using the AGREE II rigor of development and applicability domains since our guideline-specific objective was to determine how the guidelines incorporate evidence into the development and dissemination of clinical recommendations. Two independent reviewers assessed the guidelines according to the detailed instructions provided for the AGREE II.

\section{Data synthesis and statistical analysis}

We summarized categorical variables as proportions and percentages and continuous variables as means with standard deviations. All analyses were performed using Stata 13.1 [51].

\section{Results}

\section{Findings from systematic review of common eligibility criteria used across OSAT trials}

Figure 1 outlines the study screening process. We screened 5303 unique articles after removing 774 duplicates with good agreement between reviewers (kappa, 0.71 (standard error [SE] 0.02), 0.85 (SE 0.03), and 0.73 (SE 0.06) for the title, abstract, and full-text screening respectively). The title search was performed in January 2014. A list of the 60 trials included in this review is summarized in Additional file 1. During full-text review 77 articles were excluded, whereby 10 articles identified during the hand-search of Cochrane reviews were duplicates, seven studies did not review an outcome of interest, 36 studies were not randomized trials, one study showed contamination of intervention, six studies used data-linkage/retrospective data design, one study stratified all analyses by sex, and six studies were performed in a specialized population (e.g., cocaine-dependent patients).

Trials identified for inclusion evaluated the effect of methadone, buprenorphine, heroin, naltrexone (oral and implant), combination buprenorphine and naloxone, levo$\alpha$-acetylmethadol (LAAM), and morphine. Forty-five percent of trials reported establishing drug efficacy as their primary objective, $20 \%$ reported drug effectiveness as the primary trial aim, and $26 \%$ failed to explicitly state an objective. Table 1 summarizes the eligibility criteria reported across trials, as well as the percentage of opioiddependent patients from the GENOA sample $(n=394)$ who satisfy each criterion. Trials often included adult patients (100\%, all 60 trials), meeting the DSM-IV or International Classification of Disease (ICD) criteria for opioid dependence (38.3\%, 23 trials), and exclude patients with psychiatric (60\%, 36 trials) or chronic physical comorbidities (51.7 \%, 31 trials). The definitions, measurements, as well as cut-offs used to assess psychiatric and physical functioning varied substantially across trials. While some studies provide a detailed description of conditions that would deem patients ineligible for inclusion, other studies lacked such sufficient detail thus jeopardizing the reproducibility of their trial. For instance, one of the higher quality studies published in the Lancet by Schottenfeld et al. (2008) provides a list of conditions they deemed problematic for inclusion into the trial without once discussing how such conditions were measured, "Patients were ineligible if they were dependent on alcohol, benzodiazepines, or sedatives; had concentrations of liver enzymes (alkaline phosphatase or alanine transaminase) greater than three times the upper limit of normal; were dangerous to themselves or others; were psychotic or had major depression; or had life-threatening medical problems," [19]. This type of description was not uncommon, whereby the majority of studies lacked any explanation of the methods used to assess for different physical conditions or demographic characteristics.

The most restrictive criteria were the exclusion of patients with psychiatric comorbidities or those using alcohol and other substances, which alone renders $74.4 \%$ of the GENOA participants ineligible for inclusion. While not as commonly reported ( $<50 \%$ of trials), the application of other restrictive criteria such as the exclusion of patients who take psychotropic medications and the requirement for intravenous drug use behavior would render 50 and $93 \%$ of the sample ineligible for inclusion respectively.

\section{The use of evidence in clinical practice guidelines}

We identified three North American guidelines for the treatment of opioid dependence using the www.guidelines.gov database [12-14]. We identified the UK clinical practice guidelines for opioid maintenance therapy using the NICE database [52]. We also evaluated the WHO 2009 international guidelines for managing opioid-dependent patients [53]. Tables 2 and 3 summarize the recommendations made by each guideline, the grade assigned to that recommendation, evidence cited by the guideline, any cautions regarding clinical subgroup effects, the number of GENOA participants excluded by the combined eligibility criteria reported in the trials cited in the guideline, and whether the guideline discussed the populations in which the interventions were tested. 


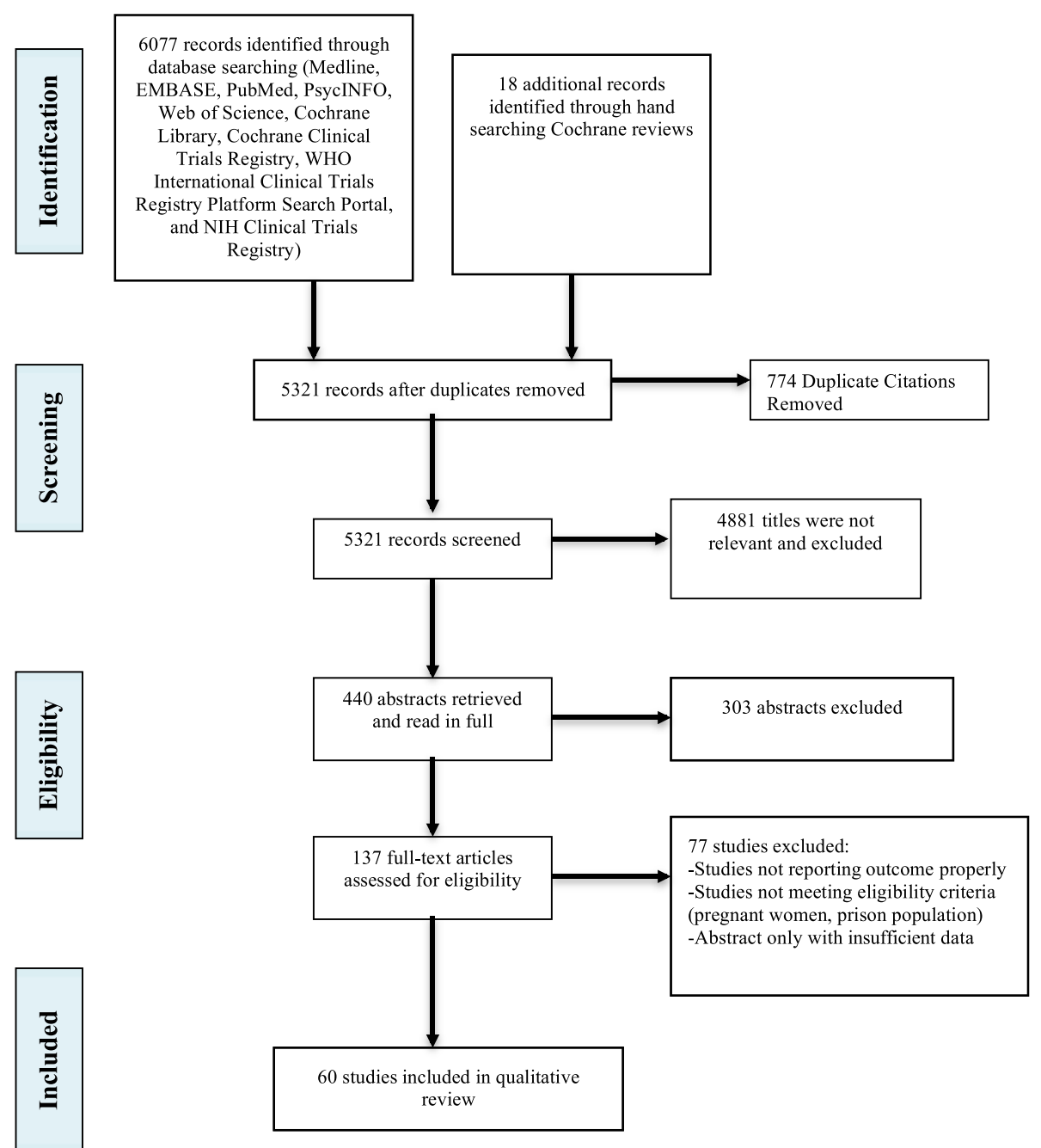

Fig. 1 Systematic review study selection flow diagram

The most recent clinical practice guidelines for management of substance use disorders from the US Department of Defense and Department of Veteran Affairs (2009) uses evidence from both trials and observational studies to inform recommendations for methadone and buprenorphine opioid substitution treatment [13]. The recommendations made within the US guidelines were based on evidence from trials excluding patients with psychiatric disorders, $[54,55]$ concurrent alcohol or poly-substance use, [54-56] and the patients prescribed psychotropic medications [55, 56]. The College of Physicians and Surgeons of Ontario published the most recent methadone guidelines, utilizing a systematic search across five databases and the grey literature [12]. The guideline committee found only four studies to address the issue of methadone effectiveness among prescription opioid users, with large weight placed on a retrospective observational study [57] and a systematic review lacking a risk of bias assessment [58]. Similar to the methadone maintenance guidelines, the Canadian guidelines for buprenorphine rely on evidence from trials and systematic reviews of studies excluding patients on psychotropic medications, and patients with serious physical comorbidities as well as concurrent substance/alcohol dependence [14]. The Canadian guidelines did not provide a description of how they evaluated the individual studies used to support their recommendations $[12,14]$. There is no explicit discussion of the risk of bias assessment conducted on the supporting body of evidence [12, 14]. When applying the criteria reported by the trials cited in each guideline we find the Canadian buprenorphine/naloxone guideline [14] are basing their recommendations on the most restrictive evidence, whereby only seven participants from the GENOA sample meet the combined eligibility requirements.

Contrary to the practices used by North American guideline panels, the NICE and WHO clinical practice 
Table 1 Summary of eligibility criteria reported across trials

\begin{tabular}{|c|c|c|}
\hline Trial eligibility criteria & $\begin{array}{l}\text { Number of trials reporting } \\
\text { criteria } k(\%),(k=60)\end{array}$ & $\begin{array}{l}\text { Number of GENOA participants } \\
\text { meeting criteria } n(\%),(n=394)\end{array}$ \\
\hline \multicolumn{3}{|l|}{ Inclusion criteria } \\
\hline Age $\geq 18$ & $30(50.0)$ & $394(100.0)$ \\
\hline DSM-IV or ICD criteria for opioid dependence & $23(38.3)$ & $394(100.0)$ \\
\hline Requirement of previous MMT Treatments or currently receiving methadone & $18(30.0)$ & $394(100.0)$ \\
\hline Provision of positive opioid urine test & $18(30.0)$ & / \\
\hline Daily injecting drug use patterns or intravenous drug use behavior & $11(18.3)$ & $28(7.1)$ \\
\hline Addiction Severity Score (i.e., $>8$ on MAP or $>12$ on ASI) & $5(8.3)$ & $168(42.6)$ \\
\hline Explicit willingness to follow methadone treatment regime & $4(6.7)$ & $394(100.0)$ \\
\hline Educational requirements (high school diploma) & $4(6.7)$ & $352(89.3)$ \\
\hline Abstinence from alcohol and other substances for 1 week prior to study entry & $3(5.0)$ & / \\
\hline Reported criminal behavior in last 6 months & $1(1.6)$ & $24(6.1)$ \\
\hline \multicolumn{3}{|l|}{ Exclusion criteria } \\
\hline Presence of psychiatric comorbidity & $36(60)$ & $293(74.4)$ \\
\hline Presence of chronic physical comorbidity & $31(51.7)$ & $225(57.1)$ \\
\hline Presence of acute physical problems & $30(50.0)$ & $106(26.9)$ \\
\hline Presence of psychotropic or neuroleptic medication & $29(48.3)$ & $193(50.0)$ \\
\hline Pregnancy & $27(45.0)$ & / \\
\hline Concurrent alcohol or substance abuse problems & $19(31.7)$ & $293(74.4)$ \\
\hline Abnormal liver enzymes & $9(15.0)$ & / \\
\hline Presence of HIV & $1(1.7)$ & $3(0.76)$ \\
\hline
\end{tabular}

I Indicates this information is not available in the GENOA sample

$\mathrm{k}$ indicates trials

Criminal behavior among GENOA participants included: drug trafficking, theft, prostitution, fraud

Psychiatric comorbidity determined using MINI psychiatric evaluation on all GENOA participants $(n=394)$

Substance use among GENOA participants included: heroin, benzodiazepine, cannabis, cocaine, crack cocaine, and alcohol

Chronic physical comorbidity was measured in the GENOA sample as a composite outcome of one or more of: HIV, chronic pain, liver disease, hepatitis, diabetes, epilepsy, or other

Acute physical problems determined in GENOA sample using MAP physical symptoms scores (participants reporting $<20$ were considered to have no acute physical health problems)

GENOA Genetics of Opioid Addiction, DSM-IV Diagnostic and Statistical Manual of Mental Disorders, Fourth Edition, ICD International Classification of Disease, MMT methadone maintenance treatment, MAP Maudsley Addiction Profile, ASI Addiction Severity Index, HIV human immunodeficiency virus, MINI The Mini International Neuropsychiatric Interview

guidelines for opioid misuse provide an appraisal of the evidence used to inform the guidance and suggest the importance of managing comorbid disorders with the use of psychosocial interventions during maintenance therapy or before using an OSAT to treat opioid dependence $[52,53]$. WHO guidelines provide explicit recommendations for managing participants with comorbid disorders (poly-substance use, pregnancy, psychiatric disorders) as well as transparency with respect to the evidence used to inform recommendations [53]. NICE guidelines provide disclaimers for the knowledge users about the populations the interventions were tested in, and the overall limitations for using the evidence to guide recommendations in specific subpopulations [52]. WHO guidelines go so far as suggesting comorbid disorders be addressed by the same consultant, a method used for increasing uptake and adherence to OSAT [53]. While WHO guidelines provided a section detailing recommendations for important subpopulations, they did not discuss any of the important issues of generalizability [53]. Moreover, WHO guidelines went so far as suggesting there was no uncertainty as to the directness of the evidence in their evidence profile for the questions, "Is methadone effective for the treatment of opioid dependence?" despite the concerning stringent inclusion criteria applied across trials [53]. In fact, the only criticisms WHO raised with respect to the generalizability of the evidence were in the case of studies performed on in-patient populations [53].

Table 4 summarizes the application of the AGREE II instrument to the guidelines. A domain-specific score is provided for each guideline in addition to the individual item scores. The UK and WHO guidelines ranked highest for the rigor of development and applicability domains (Table 4). Within this domain, UK and WHO guidelines 
Table 2 Guidelines available for evaluation of the appropriateness of opioid agonist and antagonist treatments for patients with opioid dependence

\begin{tabular}{|c|c|c|c|c|c|c|c|}
\hline Title of guideline & Country & Year & Intervention(s) assessed & Outcome & $\begin{array}{l}\text { Clinical trial design } \\
\text { characteristics in } \\
\text { supporting evidence }\end{array}$ & Use of observational studies & $\begin{array}{l}\text { Meta-analyses included } \\
\text { individual risk of bias } \\
\text { assessment }\end{array}$ \\
\hline $\begin{array}{l}\text { Clinical practice guideline } \\
\text { for management of } \\
\text { substance use disorders } \\
\text { (SUD) [13] }\end{array}$ & USA & 2009 & $\begin{array}{l}\text { Methadone and } \\
\text { buprenorphine }\end{array}$ & $\begin{array}{l}\text { Decrease in opioid use } \\
\text { (relapse prevention) }\end{array}$ & $\begin{array}{l}\text { Explanatory by design } \\
\text { with strict eligibility criteria }\end{array}$ & No & $\begin{array}{l}\text { Yes, but no discussion of } \\
\text { severe limitations of } \\
\text { included trials (allocation } \\
\text { concealment) }\end{array}$ \\
\hline $\begin{array}{l}\text { Clinical practice guideline } \\
\text { for management of } \\
\text { substance use disorders } \\
\text { (SUD) [13] }\end{array}$ & USA & 2009 & $\begin{array}{l}\text { Methadone and } \\
\text { buprenorphine }\end{array}$ & Retention in treatment & $\begin{array}{l}\text { Explanatory by design } \\
\text { with strict eligibility criteria }\end{array}$ & No & $\begin{array}{l}\text { No discussion of poor } \\
\text { methodological quality } \\
\text { of included trials and } \\
\text { estimate suffers from } \\
\text { imprecision }\end{array}$ \\
\hline $\begin{array}{l}\text { Clinical practice guideline } \\
\text { for management of } \\
\text { substance use disorders } \\
\text { (SUD) [13] }\end{array}$ & USA & 2009 & Naltrexone & $\begin{array}{l}\text { Decrease in opioid use } \\
\text { (relapse prevention) } \\
\text { and retention }\end{array}$ & $\begin{array}{l}\text { Explanatory trials by design } \\
\text { with strict eligibility criteria } \\
\text { used within meta-analysis }\end{array}$ & No & $\begin{array}{l}\text { Meta-analyses provided } \\
\text { (two with proper risk of } \\
\text { bias assessment) }\end{array}$ \\
\hline $\begin{array}{l}\text { Buprenorphine/naloxone } \\
\text { treatment for opioid } \\
\text { dependence clinical } \\
\text { practice guidelines [14] }\end{array}$ & Canada & 2011 & Buprenorphine/naloxone & $\begin{array}{l}\text { Decrease in opioid use } \\
\text { (relapse prevention) } \\
\text { and retention }\end{array}$ & $\begin{array}{l}\text { Explanatory trials by design } \\
\text { with strict eligibility criteria } \\
\text { used within meta-analysis } \\
\text { and cited trials }\end{array}$ & $\begin{array}{l}\text { Yes, retrospective chart } \\
\text { review and patient registry } \\
\text { databases }\end{array}$ & Yes \\
\hline $\begin{array}{l}\text { Methadone maintenance } \\
\text { treatment program } \\
\text { standards and clinical } \\
\text { guidelines [12] }\end{array}$ & Canada & 2011 & $\begin{array}{l}\text { Methadone maintenance } \\
\text { treatment }\end{array}$ & $\begin{array}{l}\text { Decrease in opioid use } \\
\text { (relapse prevention) }\end{array}$ & $\begin{array}{l}\text { Explanatory trials by design } \\
\text { with strict eligibility criteria } \\
\text { used within meta-analysis } \\
\text { and cited trials }\end{array}$ & Yes & $\begin{array}{l}\text { No discussion of methodology } \\
\text { of included trials used to } \\
\text { inform recommendations. } \\
\text { Systematic review } \\
\text { meta-analyses are cited. }\end{array}$ \\
\hline $\begin{array}{l}\text { Methadone and } \\
\text { buprenorphine for the } \\
\text { management of opioid } \\
\text { dependence [52] }\end{array}$ & UK & 2007 & $\begin{array}{l}\text { Methadone and } \\
\text { buprenorphine }\end{array}$ & $\begin{array}{l}\text { Decrease in opioid use } \\
\text { (relapse prevention) } \\
\text { and retention }\end{array}$ & $\begin{array}{l}\text { Explanatory trials by design } \\
\text { with strict eligibility criteria } \\
\text { used within meta-analysis } \\
\text { and cited trials }\end{array}$ & $\begin{array}{l}\text { Yes, provide evidence from } \\
\text { systematic reviews of trials } \\
\text { and non-randomized studies }\end{array}$ & $\begin{array}{l}\text { Yes (with discussion of } \\
\text { methodological limitations) }\end{array}$ \\
\hline $\begin{array}{l}\text { Guidelines for the } \\
\text { psychosocially assisted } \\
\text { pharmacological treatment } \\
\text { of opioid dependence [53] }\end{array}$ & $\begin{array}{l}\text { International } \\
\text { guidelines }\end{array}$ & 2009 & $\begin{array}{l}\text { All pharmacological } \\
\text { therapies for opioid } \\
\text { dependence }\end{array}$ & $\begin{array}{l}\text { Decrease in opioid use, } \\
\text { treatment retention }\end{array}$ & $\begin{array}{l}\text { Explanatory trials by design } \\
\text { with strict eligibility criteria } \\
\text { used within meta-analysis } \\
\text { and cited trials }\end{array}$ & $\begin{array}{l}\text { Yes, provide evidence from } \\
\text { systematic reviews of trials } \\
\text { and non-randomized studies }\end{array}$ & $\begin{array}{l}\text { Yes (with discussion of } \\
\text { methodological limitations) }\end{array}$ \\
\hline
\end{tabular}


Table 3 International guideline assessment of the evidence for substitute opioid therapy in treatment of opioid dependence (assessment of recommendations based on effect reported in literature)

\begin{tabular}{|c|c|c|c|c|c|c|c|c|}
\hline Title of guideline & $\begin{array}{l}\text { Evidence } \\
\text { provided }\end{array}$ & $\begin{array}{l}\text { Eligibility criteria used } \\
\text { across trials (including } \\
\text { criteria from trials } \\
\text { within meta-analyses } \\
\text { used as evidence) }\end{array}$ & $\begin{array}{l}\text { Grading of } \\
\text { evidence by } \\
\text { guideline } \\
\text { panel }\end{array}$ & $\begin{array}{l}\text { Reported } \\
\text { net effect of } \\
\text { intervention }\end{array}$ & Recommendation & $\begin{array}{l}\text { Guideline provided } \\
\text { caution about } \\
\text { populations the } \\
\text { intervention was } \\
\text { assessed in }\end{array}$ & Cautions & $\begin{array}{l}\text { Discussion of } \\
\text { opioid substitution } \\
\text { treatment use for } \\
\text { subpopulations } \\
\text { (psychiatric patients, } \\
\text { patients on } \\
\text { psychotropic } \\
\text { medication, } \\
\text { patients with } \\
\text { concurrent } \\
\text { poly-substance } \\
\text { use problems) }\end{array}$ \\
\hline $\begin{array}{l}\text { Clinical practice } \\
\text { guideline for } \\
\text { management } \\
\text { of substance } \\
\text { use disorders } \\
\text { (SUD) [13] } \\
\text { (Methadone } \\
\text { and buprenorphine } \\
\text { for reduction } \\
\text { in illicit opioid use) }\end{array}$ & $\begin{array}{l}{[54,55} \\
70-77]\end{array}$ & $\begin{array}{l}\text { Inclusion of patients } \\
>18 \text { with DSM-IV } \\
\text { diagnosis of opioid } \\
\text { dependence Exclusion } \\
\text { of patients with } \\
\text { psychiatric disorders, } \\
\text { concurrent substance } \\
\text { use disorders, and } \\
\text { those being prescribed } \\
\text { psychotropic medications }\end{array}$ & Good & Substantial $^{a}$ & $\begin{array}{l}\text { A strong } \\
\text { recommendation }\end{array}$ & No & $\begin{array}{l}\text { Note that buprenorphine } \\
\text { is preferred to } \\
\text { methadone in pregnant } \\
\text { women }\end{array}$ & $\begin{array}{l}\text { Yes, methadone } \\
\text { was more effective } \\
\text { than buprenorphine } \\
\text { for patients with } \\
\text { concurrent cocaine } \\
\text { dependence }\end{array}$ \\
\hline $\begin{array}{l}\text { Clinical practice } \\
\text { guideline for } \\
\text { management } \\
\text { of substance use } \\
\text { disorders (SUD) } \\
\text { [13] (Methadone } \\
\text { and buprenorphine } \\
\text { for patient } \\
\text { retention) }\end{array}$ & {$[75]$} & $\begin{array}{l}\text { Inclusion of patients }>18 \\
\text { with DSM-IV diagnosis of } \\
\text { opioid dependence } \\
\text { Exclusion of patients } \\
\text { with psychiatric disorders, } \\
\text { concurrent substance use } \\
\text { disorders, and those } \\
\text { being prescribed } \\
\text { psychotropic medications. }\end{array}$ & Good & Substantial $^{a}$ & $\begin{array}{l}\text { A strong } \\
\text { recommendation }\end{array}$ & No & None & No \\
\hline $\begin{array}{l}\text { Clinical practice } \\
\text { guideline for } \\
\text { management } \\
\text { of substance use } \\
\text { disorders (SUD) } \\
\text { [13] Naltrexone } \\
\text { for reduction in } \\
\text { illicit opioid use } \\
\text { and treatment } \\
\text { retention) }\end{array}$ & [78-80] & $\begin{array}{l}\text { Inclusion of patients }>18 \\
\text { with DSM-IV diagnosis of } \\
\text { opioid dependence } \\
\text { Exclusion of patients } \\
\text { with psychiatric disorders, } \\
\text { concurrent substance use } \\
\text { disorders, and those being } \\
\text { prescribed psychotropic } \\
\text { medications }\end{array}$ & Poor to fair & Small to moderate & $\begin{array}{l}\text { No recommendation } \\
\text { for or against the } \\
\text { routine provision } \\
\text { of the intervention } \\
\text { is made. At least fair } \\
\text { evidence was found } \\
\text { that the intervention } \\
\text { can improve health } \\
\text { outcomes, but } \\
\text { concludes that the } \\
\text { balance of benefits } \\
\text { and harms is too } \\
\text { close to justify } \\
\text { a general } \\
\text { recommendation. }\end{array}$ & No & $\begin{array}{l}\text { Suggested for use in } \\
\text { highly motivated } \\
\text { patients }\end{array}$ & $\begin{array}{l}\text { Yes, recommends } \\
\text { naltrexone within } \\
\text { highly motivated } \\
\text { patients }\end{array}$ \\
\hline
\end{tabular}


Table 3 International guideline assessment of the evidence for substitute opioid therapy in treatment of opioid dependence (assessment of recommendations based on effect reported in literature) (Continued)

\begin{tabular}{|c|c|c|c|c|c|c|c|c|}
\hline $\begin{array}{l}\text { Buprenorphine/ } \\
\text { naloxone } \\
\text { treatment } \\
\text { for opioid } \\
\text { dependence } \\
\text { clinical practice } \\
\text { guidelines[14] }\end{array}$ & [81-84] & $\begin{array}{l}\text { Inclusion of patients } \\
\text { with daily drug injection } \\
\text { behavior, } \geq 18 \text { and a } \\
\text { DSM-IV diagnosis of } \\
\text { opioid dependence } \\
\text { Exclusion of patients } \\
\text { prescribed psychotropic } \\
\text { medications, and patients } \\
\text { with serious physical } \\
\text { conditions or concurrent } \\
\text { drug/alcohol dependence }\end{array}$ & Good & Not reported & $\begin{array}{l}\text { A strong } \\
\text { recommendation }\end{array}$ & No & $\begin{array}{l}\text { A list of contraindications } \\
\text { is provided (e.g., pregnancy, } \\
\text { allergy, severe liver } \\
\text { dysfunction, acute } \\
\text { severe respiratory illness. } \\
\text { No mention of psychiatric } \\
\text { illness or concurrent } \\
\text { substance use problems. }\end{array}$ & $\begin{array}{l}\text { Yes, require no } \\
\text { concurrent } \\
\text { substance } \\
\text { use problems } \\
\text { prior to } \\
\text { buprenorphine } \\
\text { induction as well } \\
\text { as required full } \\
\text { management of } \\
\text { psychiatric } \\
\text { symptoms }\end{array}$ \\
\hline $\begin{array}{l}\text { Methadone } \\
\text { maintenance } \\
\text { treatment } \\
\text { program } \\
\text { standards } \\
\text { and clinical } \\
\text { guidelines [12] }\end{array}$ & $\begin{array}{l}{[76,} \\
85-89]\end{array}$ & $\begin{array}{l}\text { Inclusion of patients } \\
\geq 18 \text { with DSM-IV } \\
\text { diagnosis of opioid } \\
\text { dependence } 18 \text { and } \\
50 \text { years, history of } \\
\text { intravenous opioid } \\
\text { dependence, no chronic } \\
\text { medical illnesses, } \\
\text { absence of a major } \\
\text { mental illness, a negative } \\
\text { pregnancy test for } \\
\text { women, and at least } \\
3 \text { months since the } \\
\text { patient's last treatment } \\
\text { at the clinic }\end{array}$ & Not graded & Not reported & $\begin{array}{l}\text { There are guideline } \\
\text { suggestions provided } \\
\text { but no "rank" of } \\
\text { recommendation }\end{array}$ & No & $\begin{array}{l}\text { Note about treatment } \\
\text { pregnant women and } \\
\text { patients under } 18\end{array}$ & No \\
\hline $\begin{array}{l}\text { Methadone and } \\
\text { buprenorphine } \\
\text { for the management } \\
\text { of opioid } \\
\text { dependence [52] }\end{array}$ & {$[82]$} & $\begin{array}{l}\text { Inclusion of patients } \\
\geq 18 \text { with DSM-IV } \\
\text { diagnosis of opioid } \\
\text { dependence Exclusion } \\
\text { of patients with } \\
\text { psychiatric disorders, } \\
\text { comorbid substance use, } \\
\text { patients on psychotropic } \\
\text { medications }\end{array}$ & $\begin{array}{l}\text { Reported as } \\
\text { good quality } \\
\text { evidence }\end{array}$ & Not reported & $\begin{array}{l}\text { No direct } \\
\text { recommendations } \\
\text { made }\end{array}$ & $\begin{array}{l}\text { Yes, discussed the } \\
\text { populations the } \\
\text { interventions were } \\
\text { tested in and } \\
\text { explicit detailing } \\
\text { of trial design } \\
\text { characteristics }\end{array}$ & None & Yes \\
\hline
\end{tabular}


Table 3 International guideline assessment of the evidence for substitute opioid therapy in treatment of opioid dependence (assessment of recommendations based on effect reported in literature) (Continued)

\begin{tabular}{|c|c|c|c|c|c|c|c|c|}
\hline \multirow[t]{2}{*}{$\begin{array}{l}\text { Guidelines for the } \\
\text { psychosocially } \\
\text { assisted pharmacological } \\
\text { treatment of opioid } \\
\text { dependence [53] }\end{array}$} & \multirow[t]{2}{*}{$\begin{array}{l}{[76,87,} \\
90,91]\end{array}$} & $\begin{array}{l}\text { Inclusion of patients age } \\
\geq 18 \text { meeting DSM-IV } \\
\text { criteria for opioid } \\
\text { dependence with six } \\
\text { prior treatment episodes } \\
\text { at the facility running } \\
\text { the randomized trial, } \\
\text { or a single prior } \\
\text { methadone treatment, } \\
\text { and urine screen } \\
\text { positive for opioids. }\end{array}$ & \multirow[t]{2}{*}{$\begin{array}{l}\text { Moderate for } \\
\text { substance use } \\
\text { behavior and } \\
\text { high for } \\
\text { treatment } \\
\text { retention } \\
\text { (for both } \\
\text { methadone and } \\
\text { buprenorphine) }\end{array}$} & \multirow[t]{2}{*}{$\begin{array}{l}\text { Small to moderate } \\
\text { (for both opioid use } \\
\text { and retention) }\end{array}$} & \multirow[t]{2}{*}{ Strong } & \multirow[t]{2}{*}{$\begin{array}{l}\text { Yes, also a guidance } \\
\text { is provided for } \\
\text { managing specific } \\
\text { subpopulations } \\
\text { (women, patients } \\
\text { with psychiatric } \\
\text { comorbidity, } \\
\text { patients with } \\
\text { chronic pain) }\end{array}$} & \multirow[t]{2}{*}{$\begin{array}{l}\text { Note agonist therapy } \\
\text { is suggested most } \\
\text { effective, methadone } \\
\text { is preferred to } \\
\text { buprenorphine. In } \\
\text { pregnant women less } \\
\text { safety evidence is } \\
\text { available, use methadone } \\
\text { in such cases. }\end{array}$} & \multirow[t]{2}{*}{ Yes } \\
\hline & & $\begin{array}{l}\text { Exclusion of patients } \\
\text { with psychiatric or } \\
\text { chronic physical } \\
\text { comorbidities or being } \\
\text { prescribed psychotropic } \\
\text { medication, acute } \\
\text { medical condition, and } \\
\text { pregnant women }\end{array}$ & & & & & & \\
\hline
\end{tabular}

Good evidence refers to high-grade evidence (with at least one properly designed randomized trial) directly linked to health outcome

Poor to fair refers to high-grade evidence (with at least one properly designed randomized trial) linked to intermediate outcome or moderate-grade evidence (evidence obtained from well-designed cohort or case-control analytic studies, evidence obtained from multiple time series studies; dramatic results in uncontrolled experiments) directly linked to health outcome and/or refers to opinions of respected authorities; descriptive studies and case reports; reports of expert committees of evidence or no linkage of evidence to health outcome

DSM-IV Diagnostic and Statistical Manual of Mental Disorders

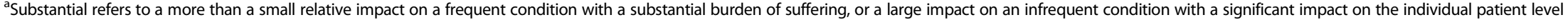


Table 4 Application of the rigor of development and applicability AGREE II domains to international guidelines for substitute opioid therapy in treatment of opioid dependence

\begin{tabular}{|c|c|c|c|c|c|}
\hline AGREE II items & $\begin{array}{l}\text { Canadian methadone } \\
\text { maintenance guideline } \\
\text { [12] score }\end{array}$ & $\begin{array}{l}\text { Canadian } \\
\text { buprenorphine } \\
\text { guideline [14] } \\
\text { score }\end{array}$ & $\begin{array}{l}\text { American } \\
\text { substance abuse } \\
\text { guideline [13] } \\
\text { score }\end{array}$ & $\begin{array}{l}\text { NICE substance } \\
\text { abuse guideline } \\
\text { [52] score }\end{array}$ & $\begin{array}{l}\text { World Health } \\
\text { Organization } \\
\text { guideline [53] } \\
\text { score }\end{array}$ \\
\hline \multicolumn{6}{|l|}{ Domain III: rigor of development } \\
\hline $\begin{array}{l}\text { Systematic methods were used to search } \\
\text { for evidence }\end{array}$ & 2 & 3 & 5 & 7 & 7 \\
\hline $\begin{array}{l}\text { The criteria for selecting the evidence are } \\
\text { clearly described }\end{array}$ & 2 & 2 & 4 & 7 & 6 \\
\hline $\begin{array}{l}\text { The strengths and limitations of the body } \\
\text { of evidence are clearly described }\end{array}$ & 1 & 2 & 2 & 6 & 7 \\
\hline $\begin{array}{l}\text { The methods for formulating the } \\
\text { recommendations are clearly described }\end{array}$ & 3 & 2 & 4 & 6 & 7 \\
\hline $\begin{array}{l}\text { The health benefits, side effects, and risks } \\
\text { have been considered in formulating the } \\
\text { recommendations }\end{array}$ & 5 & 5 & 6 & 7 & 6 \\
\hline $\begin{array}{l}\text { There is an explicit link between the } \\
\text { recommendations and the supporting } \\
\text { evidence }\end{array}$ & 4 & 3 & 4 & 6 & 7 \\
\hline $\begin{array}{l}\text { The guideline has been externally } \\
\text { reviewed by experts prior to its } \\
\text { publication }\end{array}$ & 2 & 7 & 1 & 7 & 7 \\
\hline $\begin{array}{l}\text { A procedure for updating the guideline is } \\
\text { provided }\end{array}$ & 2 & 5 & 6 & 6 & 6 \\
\hline Domain score & 27 & 44 & 50 & 93 & 95 \\
\hline \multicolumn{6}{|l|}{ Domain V: applicability } \\
\hline $\begin{array}{l}\text { The guideline describes facilitators and } \\
\text { barriers to its application }\end{array}$ & 4 & 4 & 2 & 6 & 7 \\
\hline $\begin{array}{l}\text { The guideline provides advice and/or } \\
\text { tools on how the recommendations can } \\
\text { be put into practice }\end{array}$ & 3 & 6 & 3 & 6 & 6 \\
\hline $\begin{array}{l}\text { The potential resource implications of } \\
\text { applying the recommendations have } \\
\text { been considered }\end{array}$ & 2 & 6 & 3 & 7 & 7 \\
\hline $\begin{array}{l}\text { The guideline presents monitoring and/or } \\
\text { auditing criteria }\end{array}$ & 2 & 4 & 2 & 5 & 6 \\
\hline Domain score & 29 & 67 & 25 & 86 & 93 \\
\hline
\end{tabular}

AGREE Appraisal of Guidelines for Research and Evaluation, NICE National Institute for Health and Care Excellence

scored a 93, and 95 respectively. Additionally each guideline (UK and WHO) consistently ranked 6 and 7 (strongly agree). This indicates the European guidelines use systematic methods to identify the supporting evidence in addition to being transparent about guideline development and the limitations of the evidence used to support their recommendations. The North American guidelines ranked considerably lower at 50, 44, and 27 respectively for the United States, Canadian buprenorphine, and Canadian methadone guidelines. WHO and UK guidelines again ranked highest within the applicability domain (scores 93, 86 respectively). The Canadian buprenorphine guidelines did not follow far behind with a domain score of 67. The Canadian buprenorphine guidelines spent considerable time describing the need to move buprenorphine on the all provincial drug benefit plans to ensure access for all opioid-dependent patients [14]. The American and Canadian methadone guidelines fell further behind with domain scores of 25 and 29 respectively. Table 4 provides a summary of the individual scores, allowing us to evaluate where guidelines performed weakest according to AGREE II.

\section{Discussion}

This study provides an overview of the limitations of OSAT literature, using multiple resources including results from a well-designed systematic review, [41] and an application of the findings within a clinical sample of opioid-dependent 
patients [45]. This study also provides a systematic assessment of the guidelines, highlighting the important limitations we can work to improve for the future.

Results from this systematic review suggest trials most often include adult patients meeting the DSM-IV/ICD criteria for opioid dependence with intravenous drug use behavior and a past history of methadone treatment. Trials most often exclude participants having a psychiatric or chronic physical comorbidity, current alcohol or substance use problem, as well as those taking psychotropic medications. When applying these criteria to a clinical sample of methadone patients we found them to be largely restrictive, and in some cases render $70 \%$ of the GENOA sample ineligible. Criteria such as the exclusion of participants with psychiatric or physical comorbidity, concurrent alcohol/substance use problems, as well as those using psychotropic medication appeared to have the largest cost to recruitment, where more than $50 \%$ of the GENOA sample would be lost by the application of such criteria.

The majority of international clinical practice guidelines rely on out-of-date systematic review evidence to inform guidance development as well as making strong recommendations based on many of the trials with strict eligibility that we assessed in our review. Assessment of both Canadian and American guidelines revealed concerning practices, where both panels provide numerous trials as evidence supporting recommendations for different opioid substitution treatments without once discussing the impact of trial eligibility criteria $[12,13]$. The guidelines neither acknowledge the restrictive design of the trials or the generalizability of the evidence [12-14]. The guidelines go so far as to rank the quality of the evidence as good, despite the concerning limitations we have raised for each of the cited studies [12, 13]. These issues are highlighted further when we applied the combined eligibility criteria reported by trials cited in the guidelines to the GENOA sample, whereby the highest number of GENOA participants these studies could have been generalized to would include 20 people out of 394.

Additionally, when applying the AGREE II rigor of development and applicability domains we found the North American guidelines performed considerably worse in using systematic search methods to identify research, and reporting the limitations as well as generalizability of the evidence. These practices were contrary to the transparency of reporting found in the WHO and UK guidelines. Use of the Grading of Recommendations Assessment, Development and Evaluation (GRADE) of guidelines criteria is likely impacting the stark quality differences between North American and European guidelines [59]. European guidelines provide transparent appraisal of the evidence used to inform recommendations and even go so far as cautioning the application of the evidence in psychiatric or criminal populations [52]. These findings suggest the need for North American guideline committees to evaluate and impose the critical evidence synthesis approaches utilized by the WHO and NICE.

\section{Understanding the evidence and the need for change}

The use of restrictive eligibility criteria is often set by investigators to ensure the safety for recruited patients to the new intervention being tested and to maximize the chances of observing a treatment effect under optimal conditions. Prior to phase III trials, interventions have never been tested in randomized comparison design. Entry into phase III efficacy trials is governed by restrictive eligibility criteria and conduct is often controlled by rigid protocols. This may explain why many of the trials identified for this review adhered to an explanatory design.

Testing the effect of interventions on highly specific groups may be associated with unintended harm to patients once the intervention is released for use in the general population. Our results indicate the majority of opioid substitution therapy trials exclude participants with major psychiatric disorders. This exclusion criterion is in no way novel, in fact many trials exclude patients with psychiatric comorbidities. What is concerning is the lack of understanding over what may happen to these populations once the drug is released for wider use. For example, varenicline was tested in a randomized double-blind placebo controlled trial to assess its efficacy for reducing smoking [60]. This trial excluded participants with a history of psychiatric comorbidity including: major depression requiring treatment within the past year, panic disorder, psychosis, bipolar disorder, or anorexia nervosa or bulimia [60]. Upon Food and Drug Administration (FDA) approval for use in the general population, many patients began to present with psychiatric symptoms including erratic behavior and suicide attempt [61]. Many now criticize the pharmaceutical company for marketing the use of this drug in the general population before knowing the real effect of the intervention in participants with psychiatric comorbidities, especially since smoking is prevalent among patients with psychiatric disorders. These side effects would have been better noticed had the proper implementation trials taken place, or had the intervention been tested in a more representative sample.

\section{Future directions}

There are important reasons why patients with certain comorbidities (physical, psychiatric) are excluded from trials. Efficacy trials seek to determine whether the intervention actually works under the appropriate conditions. When the objective of a trial is to determine the effect and safety of an intervention an appropriate design would be to test the intervention under optimal conditions. Patients with psychiatric comorbidities, especially those with addictive disorders are known to have difficulty complying with 
interventions, [62] and the inclusion of these participants can dilute the treatment effects we observe in trials. This trend suggests the results from stringently designed trials reporting small treatment effects are unlikely to withstand the inclusion of non-compliant patients. For instance, results from one trial show a significant hazard ratio (HR) for the comparison of buprenorphine to naltrexone for improvement of patient retention (HR: 1.56; $95 \%$ confidence interval $[\mathrm{CI}]: 1.01,2.41)$ [19]. This trial's findings are fragile and unlikely to sustain a small number of changes to the reported events across treatment arms, which would be the likely outcome had the trial been performed in a more pragmatic patient population [19].

It is important we address the need for inclusion of non-compliant participants in trials. Recognizing that patients already have challenges complying with the strict methadone treatment regimes [62], this issue is further complicated for trials recruiting addiction patients because of the high prevalence of concurrent psychiatric comorbidities [45], which are known to impact intervention adherence [62]. There have been suggestions for improving compliance among patients with psychiatric disorders; one emphasized in the literature is the use of telephone and electronic reminders [62], which has been demonstrated to improve compliance in non-psychiatric patients $[63,64]$. Other ways to improve patient compliance with addiction treatment include focusing on adherence through educational sessions with family health teams, consistent symptom measurement, and appropriate treatment tailoring [65]. Instead of excluding these participants from trials and limiting the generalizability as well as understanding of the treatment within a population representing a good portion of addiction patients, we encourage trialists to design studies with features that help increase patient compliance so to ensure an understanding of interventions effectiveness in the clinical population.

We recognize there are also other important reasons guiding the design of strict protocols, for instance the exclusion of pregnant women or patients with acute physical conditions may be a protective measure in efficacy trials where drug safety is still being determined. However, the real problem arises when we rely exclusively on evidence from these trials before we can determine the effectiveness in a "real world" sample of different types of patients (e.g., patients with comorbidities or on psychotropic medications). The limitations of the strictly designed protocols that govern efficacy and safety of trials have been largely addressed by the introduction of implementation trials, which are investigations whose primary aim is to test treatments using flexible protocols for participant selection and treatment administration. These trials often have lax eligibility criteria with the aim of including the participant we will find in the clinical practice population. However, these trials are not common in the field of addiction medicine, restricting us to the use of stringent efficacy trials to inform clinical guideline development.

Uptake in the planning and commitment to implementation or "effectiveness" research will likely stem from an increase in discussion and acceptance of the need for pragmatic trial designs. The goal in implementation trial design should be to maximize the safety of participants included in the trial while also balancing the applicability of the findings. Pragmatic trials - sometimes called implementation trials - are evaluated on a continuum and should not be characterized by a specific set of criteria [66]. We recommend future trials in addiction medicine need not abandon all "explanatory," or more stringent designs but instead work to evaluate the intervention in a wide range of participants as a secondary objective. Implementation trials should aim to include those participants with psychiatric comorbidities, poly-substance use disorders, and chronic physical conditions. Provided there are enough patients within each subgroup, researchers may be able to evaluate the mediating impact of each comorbidity and with confidence determine the true impact of physical or psychiatric abnormalities within addiction patients.

\section{Limitations}

Reliance on a treatment sample of methadone patients may potentially impact the generalizability of this study. Using the GENOA sample of participants provides a unique opportunity to demonstrate the restrictive impact of eligibility criteria reported in the addiction literature. However, demonstrating such an effect requires the use of a generalizable sample of addiction patients. Participants recruited from the CATC comprise a treatment sample, which may in fact have higher levels of comorbidities (both physical and/or psychiatric) than patients earlier on in the cycles of addiction. By the time patients are receiving pharmacological therapy for opioid dependence they are often at a later stage in their addiction course, placing them at higher risk for exposure to HIV, hepatitis, infectious disease, opioid-induced hyperalgesia, and poor social/economic living conditions. In addition, patients may only seek treatment once their physical, psychiatric, or social functioning is seriously impeded. In fact, the GENOA sample may lack the population of patients experiencing the range of problems which often coerce or force individuals into treatment altogether. However, we must also acknowledge that addiction is a complex disorder, often accompanied by serious physical and psychiatric comorbidities. Incident misuse of opioids is known to result from serious physical comorbidities such as pain [67] and from suffering experienced as a consequence of anxiety or depression [68]. Recognizing there may be discordance between prevalent users currently seeking treatment and more "incident" cases, we maintain the clinical profile of incident users also reflects a high degree of mental and 
physical abnormality. We emphasize the CATC population of patients may be a prevalent sample of addiction treatment-seeking patients, and that the results from these trials are generated to inform the treatment of such populations, and as such it is still important we demonstrate the large effect these criteria may have on weakening the directness of the evidence.

We acknowledge that observational studies are subject to selection bias, whereby patients agreeing to participate in the study may reflect a different population. To evaluate such bias we have elected to compare the demographic and clinical characteristics of participants in the GENOA study to a sample of CATC patients from four economic and geographically diverse clinics. This sample of CATC patients includes population data from four clinics and includes demographic and clinical characteristics data from all patients actively receiving treatment from these sites. Please refer to Table 5.

The GENOA sample was largely representative of the general CATC population, whereby the mean age, mean methadone dose (mg/day), prevalence of HIV, as well as marital status was not statistically significantly different between samples. There were, however, some differences, whereby the general CATC patients were shown to have a higher prevalence of hepatitis $C$ and on average a shorter treatment duration. Additionally, the general CATC sample was made up of a higher proportion of men than found in the GENOA population. These results do suggest that the GENOA participants are made up of patients with longer treatment duration and as such these patients are likely susceptible to having a higher number of physical or psychiatric comorbidities. However, these results also suggest the CATC population has a higher level of hepatitis than our sample, which may also suggest the GENOA study may be subject to a "healthy volunteer bias," whereby sicker patients are less likely to engage in the study. Inadvertently, this would bias our own results toward the null and overall suggests more participants in the "general" active treatment population would be excluded that we are purporting.

In Canada buprenorphine is not covered by the provincial drug insurance plans, and as such these patients reflect either (1) an employed population with benefits covering therapy, or (2) those patients who can afford outof-pocket coverage. In light of the administrative differences between methadone and buprenorphine coverage, we chose to include only the sample of methadone patients in the GENOA investigation, which could reflect a more marginalized population of drug treatment-seeking patients and is a potential limitation to the generalizability of the GENOA sample.

Information regarding criminal offences, sexual behavior, and domestic conflict were collected by self-report from patients agreeing to participate and thus likely underestimated due to social desirability bias. We acknowledge social desirability bias may impact the estimates for some of the demographic data collected in this study. However, we maintain important variables, such as psychiatric comorbidity, were ascertained using a validated questionnaire, the MINI. In addition, physical comorbidity (diabetes, chronic pain) was evaluated using self-report and confirmed via information logged by attending physicians in the patients' electronic medical record. Urinalysis was performed to ascertain poly-substance use. We aimed to include as many objective measurements as possible, and when unavailable we relied on safeguards such as electronic medical record confirmation.

Additionally, we may find that the definitions, measurements, and cut-offs (if relying on measurement tools) used to assess for physical and psychiatric functioning across clinical trials may be quite different than those used in the GENOA study. Thus, there is potential that the exclusion criteria reported across trials and later applied to the GENOA sample are being misused. Psychiatric comorbidity

Table 5 Comparison of the demographic and clinical characteristics of GENOA participants to the general population of CATC patients

\begin{tabular}{llll}
\hline Demographic and clinical characteristics & CATC population level data, $N=1354$ & GENOA sample, $n=394$ & $\begin{array}{l}\text { Statistical significance observed } \\
\text { testing differences between groups }\end{array}$ \\
\hline Mean age (SD) & $38.4(10.7)$ & $38.5(10.9)$ & 0.87 \\
Sex (percentage male) & 66.9 & 53.3 & $p<0.05$ \\
Mean duration on MMT in years (SD) & $2.1(1.2)$ & $4.3(4)$ & $p<0.05$ \\
Mean methadone dose in mg per day (SD) & $81.9(53.5)$ & $78.1(41.2)$ & 0.19 \\
Hepatitis C positive \% & 29.9 & 22.3 & $p<0.05$ \\
HIV positive \% & 0.3 & 0.8 & 0.19 \\
Marital status (\% single, divorced) & 64.8 & 68.2 & 0.19
\end{tabular}

Two-sample t test used to assess for differences between groups (CATC and GENOA) for continuous values

Chi-square test used to assess for differences between groups for categorical variables

GENOA Genetics of Opioid Addiction, CATC Canadian Addiction Treatment Centres, SD standard deviation, MMT methadone maintenance treatment, HIV human immunodeficiency virus 
can vary from obvious psychotic disorders to any anxiety or depressive disorder. Depending on the thoroughness of the trial investigators and indeed the thoroughness of the clinicians administering the GENOA assessment tools (MINI, BPI, MAP), differing rates of psychiatric problems will be identified and could compromise the aims of our study. Due to the serious limitations in reporting of the definitions and measurements for many of the eligibility criteria discussed across the literature, we caution the interpretation of the application of such criteria using the GENOA study.

Provided we had reliable data on the medical and demographic characteristics of opioid addiction patients, we would be better equipped to demonstrate the clinical guidelines are not appropriate for the US and UK populations. Administrative data provided by Health Maintenance Organizations in the US or the National Health Service in the UK could serve as sources for population-level data. However, the quality of this data is questionable due to the high susceptibility for misclassification. A recent study evaluated the misclassification of psychiatric disorders based on the comparison of medical records and administrative data and found only moderate agreement for any mental comorbidity [69]. We acknowledge the problems associated with opioid dependence are impacted by the health, social, and judicial systems, which can vary across countries. However, to say the prevalence of psychiatric and physical comorbidity, as well as prescription of psychotropic medication varies so much between countries, as well as types of addiction populations such that it would render the larger message of this study insignificant is improbable.

\section{Conclusions}

Findings from our analysis of the literature as well as application of common eligibility criteria to a clinical sample of patients with opioid use disorder demonstrate large differences between the trial and clinical population of opioid-dependent patients. Evaluation of the global context and impact of these findings shows the concerning state of addiction medicine, where we find the majority of studies used to inform clinical practice are not generalizable to the population seen in clinical practice. When more than $50 \%$ of the addiction patient population suffers with comorbid psychiatric conditions, yet only a small fraction of the evidence used to inform the current treatment strategies for these patients is tested on patients with psychiatric conditions we are faced with a critical dilemma. Are we providing the appropriate treatments? Are we completing our due diligence to this patient population? Are we possibly putting our patients at risk? These questions cannot be answered until the appropriate re-evaluation of the evidence takes place using pragmatic trial designs and implementation studies.

\section{Additional file}

Additional file 1: Table outlining description of studies included in the systematic review. (PDF $262 \mathrm{~kb}$ )

\section{Abbreviations}

AGREE: Appraisal of Guidelines for Research and Evaluation; ASI: Addiction Severity Index; BPI: Brief Pain Inventory; CATC: Canadian Addiction Treatment Centres; Cl: confidence interval; CTR: Clinical Trials Registry; DSM-IV: Diagnostic and Statistical Manual of Mental Disorders, Fourth Edition; EMBASE: Excerpta Medica DataBase; FDA: Food and Drug Administration; GENOA: Genetics of Opioid Addiction; GRADE: Grading of Recommendations Assessment, Development and Evaluation; HIV: human immunodeficiency virus; HR: hazard ratio; ICD: International Classification of Disease; LAAM: levo-a-acetylmethadol; MAP: Maudsley Addiction Profile; MINI: The Mini International Neuropsychiatric Interview; MMT: methadone maintenance treatment; NICE: National Institute for Health and Care Excellence; NIH: National Institutes of Health; OATC: Ontario Addiction Treatment Centres; OSAT: opioid substitution and antagonist therapy; OST: opioid substitution therapy; PRISMA: Preferred Reporting Items for Systematic reviews and Meta-Analyses; RCT: randomized controlled trial; SD: standard deviation; SE: standard error; WHO: World Health Organization; UK: United Kingdom; US: United States.

\section{Competing interests}

The authors declare that they have no competing interests.

\section{Authors' contributions}

$B B D, L T$, and $Z S$ were responsible for the development of the research question and protocol for this study. BBD, LN, and MB were responsible for title, abstract, and full-text screening, as well as data abstraction for all trials included in the systematic review. BBD was responsible for all statistical analyses performed in this investigation. All authors $(B B D, P R, L N, M B, J P, C P$, $\mathrm{GP}, \mathrm{MV}, J \mathrm{D}, \mathrm{AW}, \mathrm{DM}, \mathrm{DD}, \mathrm{ZS}$, and $\mathrm{LT}$ ) contributed equally during the drafting of the protocol, data collection, planning of analyses, and writing of the manuscript. BBD had full access to all the data in the study and takes responsibility for the integrity of the data and the accuracy of the data analysis. All authors read and approved the final manuscript.

\section{Acknowledgments}

We would like to sincerely thank everyone who contributed to the successful completion of the GENOA investigation. This work was supported by Canadian Institutes of Health Research (CIHR) Drug Safety and Effectiveness Network (DSEN) grant (grant number: 126639) and the Peter Boris Centre for Addictions Research, St. Joseph's Healthcare Hamilton. Brittany B. Dennis and Monica Bawor are supported by the Intersections of Mental Health Perspectives in Addictions Research Training (IMPART) research fellowship funded through $\mathrm{CIHR}$ and the British Columbia Centre of Excellence for Women's Health. Brittany B. Dennis is also supported by the David L. Sackett Scholarship. Pavel S. Roshanov is supported by the American Society of Nephrology Student Scholar Grant and a CIHR-Institute for Health Services and Policy Research Rising Star Award. The funders had no role in study design and conduct of the study; collection, management, analysis, and interpretation of the data; and preparation, review, or approval of the manuscript, and decision to submit the manuscript for publication.

This work was only possible through the great collaborative work between GENOA and the Ontario Addiction Treatment Centres (OATC) network of clinical sites. We would like to also extend our genuine gratitude to all the participants from the OATC facilities who generously donated their time, information and samples. We also thank the OATC clinical staff for all their great work on patient recruitment and data collection.

\section{Author details}

${ }^{1}$ Department of Clinical Epidemiology and Biostatistics, McMaster University, 1280 Main Street West, Hamilton, ON L8S 4L8, Canada. ${ }^{2}$ Schulich School of Medicine and Dentistry, University of Western Ontario, 4, 1465 Richmond Street, London, ON N6G 2M1, Canada. ${ }^{3}$ Michael G. Degroote School of Medicine, McMaster University, 1280 Main Street West, Hamilton, ON L8S 4L8, Canada. ${ }^{4}$ McMaster Integrative Neuroscience Discovery and Study Program, McMaster University, 1280 Main Street West, Hamilton, ON L8S 4L8, Canada. ${ }^{5}$ Department of Anesthesia, McMaster University, 1280 Main Street 
West, Hamilton, ON L8S 4L8, Canada. ${ }^{6}$ Canadian Addiction Treatment Centres, 13291 Yonge Street, Richmond Hill, ON L4E 4L6, Canada. ${ }^{7}$ Department of Medicine, Hamilton General Hospital, 237 Barton St East, Hamilton, ON L8L 2X2, Canada. ${ }^{8}$ Northern Ontario School of Medicine, Ramsey Lake Road, Sudbury, ON POM, Canada. ${ }^{9}$ Population Genomics Program, Chanchlani Research Centre, McMaster University, 1280 Main Street West, Hamilton, ON L8S 4K1, Canada. ${ }^{10}$ Peter Boris Centre for Addictions Research, St. Joseph's Healthcare Hamilton, 100 West 5th Street, Hamilton, ON L9C OE3, Canada. ${ }^{11}$ Department of Psychiatry and Behavioural Neurosciences, McMaster University, 1280 Main Street West, Hamilton, ON L8S 4K1, Canada. ${ }^{12}$ Centre for Evaluation of Medicine, 25 Main Street West, Hamilton, ON L8P 1H1, Canada. ${ }^{13}$ System Linked Research Unit, 175 Longwood Road, South Hamilton L8P OA1, Canada.

Received: 12 March 2015 Accepted: 3 September 2015 Published online: 21 October 2015

\section{References}

1. Zapata JT, Katims DS, Yin Z. A two-year study of patterns and predictors of substance use among Mexican American youth. Adolescence. 1998;33:391-403.

2. Kilpatrick DG, Acierno R, Saunders B, Resnick HS, Best CL, Schnurr PP. Risk factors for adolescent substance abuse and dependence: data from a national sample. J Consult Clin Psychol. 2000;68:19-30.

3. Grant BF, Goldstein RB, Chou SP, Huang B, Stinson FS, Dawson DA, et al. Sociodemographic and psychopathologic predictors of first incidence of DSM-IV substance use, mood and anxiety disorders: results from the Wave 2 National Epidemiologic Survey on Alcohol and Related Conditions. Mol Psychiatry. 2009;14:1051-66.

4. United Nations Office on Drugs and Crime. World Drug Report. Vienna, Austria: United Nations; 2015. (United Nations publication, Sales No. E.15.XI.6).

5. Substance Abuse and Mental Health Services Administration OAS. Results from the 2012 National Survey on Drug Use and Health: summary of national findings. In: NSDUH Series H-46. Rockville: Substance Abuse and Mental Health Services Administration; 2013.

6. Birnbaum HG, White AG, Schiller M, Waldman T, Cleveland JM, Roland CL. Societal costs of prescription opioid abuse, dependence, and misuse in the United States. Pain Med. 2011;12:657-67.

7. Disley E, Mulcahy A, Pardal M, Rubin J, Ruggeri K. Development of a framework to estimate the cost of opioid dependence. Cambridge, UK: RAND Europe; 2013

8. World Health Organization. World Drug Report. New York: United Nations Offices on Drugs and Crime (UNODC); 2012

9. Center for Substance Abuse Treatment. Medication-assisted treatment for opioid addiction in opioid treatment programs, Treatment improvement protocol (TIP) Series 43: DHHS Publication No. (SMA) 05-4048. Rockville: Substance Abuse and Mental Health Services Administration; 2005

10. Substance Abuse and Mental Health Services Administration OAS. Treatment episode data set (TEDS): 2005 discharges from substance abuse treatment services, DASIS Series S-41, DHHS Publication No. (SMA) 08-4314. Rockville: Substance Abuse and Mental Health Services Administration; 2008.

11. Clausen T, Anchersen K, Waal H. Mortality prior to, during and after opioid maintenance treatment (OMT): a national prospective cross-registry study. Drug Alcohol Depend. 2008;94:151-7.

12. The College of Physicians and Surgeons of Ontario. Methadone maintenance treatment program standards and clinical guidelines. 4th ed. Toronto: The College of Physicians and Surgeons of Ontario; 2011.

13. Veterans Affairs/Department of Defense clinical practice guideline for management of substance use disorders (SUD). Washington (DC): Veterans Health Association, Department of Defense; 2009.

14. Handford C, Kahan M, Srivastava A, Cirone S, Sanghera S, Palda V, et al. Buprenorphine/naloxone for opioid dependence: clinical practice guideline. Toronto: Centre for Addiction and Mental Health; 2011. Available at http:// www.guideline.gov/content.aspx?id=39351\&search=methadone.

15. National Collaborating Centre for Mental Health. Drug misuse: opioid detoxification. Leicester and London: The British Psychological Society and the Royal College of Psychiatrists; 2008.

16. Van Spall HG, Toren A, Kiss A, Fowler RA. Eligibility criteria of randomized controlled trials published in high-impact general medical journals: a systematic sampling review. JAMA. 2007;297:1233-40.
17. Fudala PJ, Bridge TP, Herbert S, Williford WO, Chiang CN, Jones K, et al. Office-based treatment of opiate addiction with a sublingual-tablet formulation of buprenorphine and naloxone. N Engl J Med. 2003;349:949-58.

18. Johnson RE, Jaffe JH, Fudala PJ. A controlled trial of buprenorphine treatment for opioid dependence. JAMA. 1992;267:2750-5.

19. Schottenfeld RS, Chawarski MC, Mazlan M. Maintenance treatment with buprenorphine and naltrexone for heroin dependence in Malaysia: a randomised, double-blind, placebo-controlled trial. Lancet. 2008;371:2192-200.

20. Sees KL, Delucchi KL, Masson C, Rosen A, Clark HW, Robillard H, et al. Methadone maintenance vs 180-day psychosocially enriched detoxification for treatment of opioid dependence: a randomized controlled trial. JAMA. 2000;283:1303-10.

21. Eissenberg T, Bigelow GE, Strain EC, Walsh SL, Brooner RK, Stitzer ML, et al Dose-related efficacy of levomethadyl acetate for treatment of opioid dependence. A randomized clinical trial. JAMA. 1997;277:1945-51.

22. Oviedo-Joekes E, Brissette S, Marsh DC, Lauzon P, Guh D, Anis A, et al. Diacetylmorphine versus methadone for the treatment of opioid addiction. N Engl J Med. 2009;361:777-86

23. Woody GE, Poole SA, Subramaniam G, Dugosh K, Bogenschutz M, Abbott $P$, et al. Extended vs short-term buprenorphine-naloxone for treatment of opioid-addicted youth: a randomized trial. JAMA. 2008:300:2003-11.

24. Kakko J, Svanborg KD, Kreek MJ, Heilig M. 1-year retention and social function after buprenorphine-assisted relapse prevention treatment for heroin dependence in Sweden: a randomised, placebo-controlled trial. Lancet. 2003;361:662-8.

25. Strain EC, Bigelow GE, Liebson IA, Stitzer ML. Moderate- vs high-dose methadone in the treatment of opioid dependence: a randomized trial. JAMA. 1999:281:1000-5.

26. Rondinelli AJ, Ouellet $\sqcup$, Strathdee SA, Latka MH, Hudson SM, Hagan H, et al. Young adult injection drug users in the United States continue to practice HIV risk behaviors. Drug Alcohol Depend. 2009;104:167-74.

27. Darke S, Kaye S, McKetin R, Duflou J. Major physical and psychologica harms of methamphetamine use. Drug Alcohol Rev. 2008;27:253-62.

28. Darke $S$, Hall W. Levels and correlates of polydrug use among heroin users and regular amphetamine users. Drug Alcohol Depend. 1995;39:231-5.

29. Wu LT, Woody GE, Yang C, Blazer DG. How do prescription opioid users differ from users of heroin or other drugs in psychopathology: results from the National Epidemiologic Survey on Alcohol and Related Conditions. J Addict Med. 2011;5:28-35

30. Pilowsky DJ, Wu LT, Burchett B, Blazer DG, Woody GE, Ling W. Co-occurring amphetamine use and associated medical and psychiatric comorbidity among opioid-dependent adults: results from the Clinical Trials Network. Subst Abuse Rehabil. 2011;2:133-44

31. Kosten TR, Rounsaville BJ, Kleber HD. A 2.5-year follow-up of depression, life crises, and treatment effects on abstinence among opioid addicts. Arch Gen Psychiatry. 1986;43:733-8.

32. Compton 3rd WM, Cottler LB, Jacobs JL, Ben-Abdallah A, Spitznagel EL. The role of psychiatric disorders in predicting drug dependence treatment outcomes. Am J Psychiatry. 2003;160:890-5.

33. Rounsaville BJ, Weissman MM, Crits-Christoph K, Wilber C, Kleber H. Diagnosis and symptoms of depression in opiate addicts. Course and relationship to treatment outcome. Arch Gen Psychiatry. 1982;39:151-6.

34. Rounsaville BJ, Kosten TR, Weissman MM, Kleber HD. Prognostic significance of psychopathology in treated opiate addicts. A 2.5-year follow-up study. Arch Gen Psychiatry. 1986:43:739-45.

35. Storbjork J. Implications of enrolment eligibility criteria in alcohol treatment outcome research: generalisability and potential bias in 1- and 6-year outcomes. Drug Alcohol Rev. 2014;33:604-11.

36. Finney JW. Limitations in using existing alcohol treatment trials to develop practice guidelines. Addiction. 2000;95:1491-500.

37. Blanco C, Olfson M, Okuda M, Nunes EV, Liu SM, Hasin DS. Generalizability of clinical trials for alcohol dependence to community samples. Drug Alcohol Depend. 2008;98:123-8.

38. Humphreys K, Weisner C. Use of exclusion criteria in selecting research subjects and its effect on the generalizability of alcohol treatment outcome studies. Am J Psychiatry. 2000;157:588-94.

39. Okuda M, Hasin DS, Olfson M, Khan SS, Nunes EV, Montoya I, et al. Generalizability of clinical trials for cannabis dependence to community samples. Drug Alcohol Depend. 2010;111:177-81. 
40. Humphreys K, Harris AH, Weingardt KR. Subject eligibility criteria can substantially influence the results of alcohol-treatment outcome research. J Stud Alcohol Drugs. 2008;69:757-64.

41. Dennis BB, Naji L, Bawor M, Bonner A, Varenbut M, Daiter J, et al. The effectiveness of opioid substitution treatments for patients with opioid dependence: a systematic review and multiple treatment comparison protocol. Syst Rev. 2014;3:105.

42. Higgins JPT, Green S, editors. The Cochrane Handbook for Systematic Reviews of Interventions Version 5.1.0: The Cochrane Collaboration. 2011.

43. Cohen J. A coefficient of agreement for nominal scales. Educ Psychol Meas. 1960;20:37-46.

44. Liberati A, Altman DG, Tetzlaff J, Mulrow C, Gotzsche PC, loannidis JP, et al. The PRISMA statement for reporting systematic reviews and meta-analyses of studies that evaluate healthcare interventions: explanation and elaboration. BMJ. 2009;339:b2700.

45. Samaan Z, Bawor M, Dennis B, Plater C, Worster A, Varenbut M, et al. Genetic influence in methadone dose and response to treatment in patients undergoing methadone maintenance treatment (MMT) for opioid addiction: a pilot study. Neuropsychiatr Dis Treat. 2014;10:1503-8.

46. Cleeland C. The brief pain inventory: user guide. Houston: Pain Research Group; 1991

47. Sheehan DV, Lecrubier $Y$, Sheehan $\mathrm{KH}$, Amorim P, Janavs J, Weiller $E$, et al. The Mini-International Neuropsychiatric Interview (M.I.N.I.): the development and validation of a structured diagnostic psychiatric interview for DSM-IV and ICD-10. J Clin Psychiatry. 1998;59 Suppl 20:22-33. quiz 34-57.

48. Marsden J, Gossop M, Stewart D, Best D, Farrell M, Lehmann P, et al. The Maudsley Addiction Profile (MAP): a brief instrument for assessing treatment outcome. Addiction. 1998;93:1857-67.

49. Brouwers MC, Kho ME, Browman GP, Burgers JS, Cluzeau F, Feder G, et al. AGREE II: advancing guideline development, reporting and evaluation in health care. J Clin Epidemiol. 2010;63:1308-11.

50. Brouwers MC, Kho ME, Browman GP, Burgers JS, Cluzeau F, Feder G, et al. Development of the AGREE II, part 2: assessment of validity of items and tools to support application. CMAJ. 2010;182:E472-8.

51. StataCorp. Stata Statistical Software: Release 12. College Station, TX: StataCorp LP; 2009

52. National Treatment Association Guidance. Methadone and buprenorphine for the management of opioid dependence. London, UK: National Institute for Health and Care Excellence; 2007.

53. World Health Organization. Guidelines for the psychosocially assisted pharmacological treatment of opioid dependence. Geneva: World Health Organization; 2009.

54. Schottenfeld RS, Chawarski MC, Pakes JR, Pantalon MV, Carroll KM, Kosten TR. Methadone versus buprenorphine with contingency management or performance feedback for cocaine and opioid dependence. Am J Psychiatry. 2005;162:340-9.

55. Neri S, Bruno CM, Pulvirenti D, Malaguarnera M, Italiano C, Mauceri B, et al. Randomized clinical trial to compare the effects of methadone and buprenorphine on the immune system in drug abusers. Psychopharmacology (Berl). 2005;179:700-4.

56. Mattick Richard P, Kimber J, Breen C, Davoli M. Buprenorphine maintenance versus placebo or methadone maintenance for opioid dependence. Cochrane Database Syst Rev. 2014;2:CD002207.

57. Banta-Green CJ, Maynard C, Koepsell TD, Wells EA, Donovan DM. Retention in methadone maintenance drug treatment for prescription-type opioid primary users compared to heroin users. Addiction. 2009;104:775-83.

58. Johansson BA, Berglund M, Lindgren A. Efficacy of maintenance treatment with methadone for opioid dependence: a meta-analytical study. Nord J Psychiatry. 2007;61:288-95.

59. Guyatt G, Oxman AD, Akl EA, Kunz R, Vist G, Brozek J, et al. GRADE guidelines: 1. Introduction-GRADE evidence profiles and summary of findings tables. J Clin Epidemiol. 2011;64:383-94.

60. Nides M, Oncken C, Gonzales D, Rennard S, Watsky EJ, Anziano R, et al. Smoking cessation with varenicline, a selective alpha4beta2 nicotinic recepto partial agonist: results from a 7-week, randomized, placebo- and bupropioncontrolled trial with 1-year follow-up. Arch Intern Med. 2006;166:1561-8.

61. Westly E: Why do clinical trials exclude depressed people? In: Reuters. New York, NY. 2011-03-18.

62. Glyngdal P, Sorensen P, Kistrup K. Non-compliance in community psychiatry: failed appointments in the referral system to psychiatric outpatient treatment. Nord J Psychiatry. 2002;56:151-6.
63. Mbuagbaw L, van der Kop ML, Lester RT, Thirumurthy $H$, Pop-Eleches C, Ye $C$, et al. Mobile phone text messages for improving adherence to antiretroviral therapy (ART): an individual patient data meta-analysis of randomised trials. BMJ Open. 2013;3:e003950.

64. Mbuagbaw L, Thabane L, Ongolo-Zogo P. Opening communication channels with people living with HIV using mobile phone text messaging: insights from the CAMPS trial. BMC Res Notes. 2013;6:131.

65. Kane JM. Improving patient outcomes in schizophrenia: achieving remission, preventing relapse, and measuring success. J Clin Psychiatry. 2013;74:e18

66. Schwartz D, Lellouch J. Explanatory and pragmatic attitudes in therapeutical trials. J Chronic Dis. 1967;20:637-48.

67. Vowles KE, McEntee ML, Julnes PS, Frohe T, Ney JP, van der Goes DN. Rates of opioid misuse, abuse, and addiction in chronic pain: a systematic review and data synthesis. Pain. 2015;156:569-76.

68. Kessler RC. The epidemiology of dual diagnosis. Biol Psychiatry. 2004:56:730-7.

69. Marrie RA, Fisk JD, Yu BN, Leung S, Elliott L, Caetano P, et al. Mental comorbidity and multiple sclerosis: validating administrative data to support population-based surveillance. BMC Neurol. 2013;13:16.

70. Farre M, Mas A, Torrens M, Moreno V, Cami J. Retention rate and illicit opioid use during methadone maintenance interventions: a meta-analysis. Drug Alcohol Depend. 2002;65:283-90.

71. Fischer B, Cruz MF, Rehm J. Illicit opioid use and its key characteristics: a select overview and evidence from a Canadian multisite cohort of illicit opioid users (OPICAN). Can J Psychiatry. 2006;51:624-34.

72. Johnson RE, Chutuape MA, Strain EC, Walsh SL, Stitzer ML, Bigelow GE. A comparison of levomethadyl acetate, buprenorphine, and methadone for opioid dependence. N Engl J Med. 2000;343:1290-7.

73. Lintzeris N, Ritter A, Panjari M, Clark N, Kutin J, Bammer G. Implementing buprenorphine treatment in community settings in Australia: experiences from the Buprenorphine Implementation Trial. Am J Addict. 2004;13 Suppl 1:S29-41

74. Marsch LA. The efficacy of methadone maintenance interventions in reducing illicit opiate use, HIV risk behavior and criminality: a meta-analysis. Addiction. 1998;93:515-32.

75. Mattick RP, Ali R, White JM, O'Brien S, Wolk S, Danz C. Buprenorphine versus methadone maintenance therapy: a randomized double-blind trial with 405 opioid-dependent patients. Addiction. 2003;98:441-52.

76. Strain EC, Stitzer ML, Liebson IA, Bigelow GE. Dose-response effects of methadone in the treatment of opioid dependence. Ann Intern Med. 1993:119:23-7.

77. Strain EC, Stitzer ML, Liebson IA, Bigelow GE. Methadone dose and treatment outcome. Drug Alcohol Depend. 1993;33:105-17.

78. Adi Y, Juarez-Garcia A, Wang D, Jowett S, Frew E, Day E, et al. Ora naltrexone as a treatment for relapse prevention in formerly opioid-dependent drug users: a systematic review and economic evaluation. Health Technol Assess. 2007; 11:iii-iv. 1-85.

79. Minozzi S, Amato L, Vecchi S, Davoli M, Kirchmayer U, Verster A. Oral naltrexone maintenance treatment for opioid dependence. Cochrane Database Syst Rev 2006:CD001333. doi:10.1002/14651858.CD001333.pub2.

80. Johansson BA, Berglund M, Lindgren A. Efficacy of maintenance treatment with naltrexone for opioid dependence: a meta-analytical review. Addiction. 2006;101:491-503.

81. Mattick RP, Kimber J, Breen C, Davoli M. Buprenorphine maintenance versus placebo or methadone maintenance for opioid dependence. Cochrane Database Syst Rev 2009:CD002207. doi:10.1002/14651858.CD002207.pub3.

82. Connock M, Juarez-Garcia A, Jowett S, Frew E, Liu Z, Taylor RJ. Methadone and buprenorphine for the management of opioid dependence: a systematic review and economic evaluation. Health Technol Assess. 2007;11:1-171. iii-iv.

83. Ahmadi JFH, Farrashbandi H, Moosavinasab M, Babaee M, Firoozabadi A Mohagheghzadeh $\mathrm{M}$, et al. Treatment of heroin dependence. Ger J Psychiatry. 2004;7:1-5.

84. Ahmadi JMI, Ahmadi M. Treatment of intravenous buprenorphine dependence: a randomized open clinical trial. Ger J Psychiatry. 2006;6:23-9.

85. Gunne LM, Gronbladh L. The Swedish methadone maintenance program: a controlled study. Drug Alcohol Depend. 1981;7:249-56.

86. Kinlock TW, Gordon MS, Schwartz RP, Fitzgerald TT, O'Grady KE. A randomized clinical trial of methadone maintenance for prisoners: results at 12 months postrelease. J Subst Abuse Treat. 2009;37:277-85. 
87. Newman RG, Whitehill WB. Double-blind comparison of methadone and placebo maintenance treatments of narcotic addicts in Hong Kong. Lancet. 1979;2:485-8.

88. Mattick RP, Breen C, Kimber J, Davoli M. Methadone maintenance therapy versus no opioid replacement therapy for opioid dependence. Cochrane Database Syst Rev. 2003;CD002209.

89. Yancovitz SR, Des Jarlais DC, Peyser NP, Drew E, Friedmann P, Trigg HL, et al. A randomized trial of an interim methadone maintenance clinic. Am J Public Health. 1991;81:1185-91.

90. Vanichseni S, Wongsuwan B, Choopanya K, Wongpanich K. A controlled trial of methadone maintenance in a population of intravenous drug users in Bangkok: implications for prevention of HIV. Int J Addict. 1991;26:1313-20.

91. Johnson RE, Eissenberg T, Stitzer ML, Strain EC, Liebson IA, Bigelow GE. A placebo controlled clinical trial of buprenorphine as a treatment for opioid dependence. Drug Alcohol Depend. 1995;40:17-25.

\section{Submit your next manuscript to BioMed Central and take full advantage of:}

- Convenient online submission

- Thorough peer review

- No space constraints or color figure charges

- Immediate publication on acceptance

- Inclusion in PubMed, CAS, Scopus and Google Scholar

- Research which is freely available for redistribution 